\title{
What's In a Name? \\ Depersonalization at the Hands of the State Chester Abbotsbury *
}

ticks and stones may break my bones, and names can never hurt me, but
the various façades we present in the different situation reflect aspects of us not always initially apparent. When I first arrived at the Don Gaol, one of the hardest things for me to get used to was the fact that few of the men incarcerated there used their "government names". Many from the so-called criminal sub-culture, or rather the oppressed underclass that feels constantly at odds with the system, adopt a street name long before a first arrest is made. These alter egos foster a semblance of an artificial identity and an orchestrated outward manifestation of persona at the time. A nom de guerre, if you will, is used to maintain some degree of anonymity in the eyes of the surveillance State, a system that the adopter does not see a viable means of otherwise functioning within.

Artificial monikers also serve to distance people from each other through the creation of the proxy identity. The legal, familial, and vulnerable parts of the person are discarded wholesale in favour of a fabricated veneer of bravado and success. In many cases the artifice is a consequence of the only, and perhaps criminal, options the underlying, disadvantaged citizen deems available to subsist or succeed. It is thus the packaged persona, acting as proxy, who gets caught by the police and subsequently jailed, as opposed to the underlying person themselves. Mom might be disappointed that her son Jerome is a criminal, but the fact only serves to bolster the legend of "Jericho" the persona. Some broad sociological generalizations might be inferred from such distinctions.

The criminal class follows a different set of rules entirely from the ones citizens and squares take for granted. There is thus a substantial demographic of people running around this country leading ostensibly suspicious and decidedly desperate lives at the boundaries of our society. We are quick to make extra room on the sidewalk for the hooligan with the still-stickered sideways-pointing-bill baseball hat to pass us quickly by without further interaction. But beyond noticing a member of a marginalized economic underclass on the street so that we can avoid contact, we categorically ignore those who fall too far outside mainstream society.

Marginalized, that is, except by corporate wolves that package and commodify "street" culture. It is no secret that global consumer brands are ever on the lookout for fads in the inner cities, later adopted as the 
next hot urban fashion by suburban teens far removed from the plights of the disadvantaged. I remember being in a brainstorming session for a New York-based mobile company when the lawyer said "You want cool? Does anybody know what I mean when I say 'street'?" Yeah, that is how fat white guys earning six-figure salaries euphemize and romanticize cultures they want nothing to do with unless they can profit from exploiting them. This exercise in branding and marketing is a perfect metaphor, if not a cause in and of itself, of the phenomenon of street names.

Remember that conspicuous consumption requires income and that is where the system breaks down. My own experiences as a school tutor in prison lead me to conclude that a great many of my fellow prisoners are being cast out and refused normal education and employment. The reasons are mainly cultural - perhaps because they have tattoos on their necks bearing a girlfriend's name, use a lexicon that will never be considered for inclusion in the Oxford Dictionary, or braid their hair in corn-rows. It could be their accents or cultural practices still evident from their countries of origin in the patchwork quilt that is Canada.

Maybe the schools depend too heavily on parental assistance in the learning process and not everyone has a home-maker mom who can help with the week's spelling list. Maybe the standardized curriculum subject matter in schools is only really interesting to certain sub-sets of the Canadian ethnic make-up, a mix of cultures that changes drastically between innercity, suburb and countryside. Is it any wonder that disaffected youth adopt new personalities, ones that exude confidence, strength, and success, when their attempts to fit into the system that would use their given names are met with failure, indifference, and even contempt for their inherited or more recently created cultures?

I am stunned at the number of illiterate people I have encountered in this part of the system. It is well acknowledged that the average reading ability in prison is at a Grade 8 level. Recall that an average is based on a sample set that exists both above and below it. Looked upon like that, half of prisoners read below a Grade 8 level. It takes a pervasive systemic fault, perhaps even a concerted effort on the part of those orchestrating and administering it for someone to go through the majority of the highly funded Canadian primary education system without learning how to read. There must be something in that system that fails them, whether it is content and process, or perception and attitude. It is even more difficult to identify root causes 
by making sweeping generalizations about the worlds the people who fall through the cracks come from, the effects being obvious. For them, any mention of their given name, the one bestowed upon them by their parents, reminds the increasingly disadvantaged citizen of their perceived failure to participate in the system. It is easier to rename oneself than to remake the system that marginalizes.

So many in our society are shunted aside and quietly passed along once it is realized that they have fallen behind the norm in achievement and skill. These individuals require too much work, energy, attention and love to bring up to the level of their classmates or colleagues, to the level of everyday citizens to participate in the economy. This happens most frequently in lower income neighbourhoods where there exists more single parent families, domestic violence, addiction and the crippling poverty that keeps parents and siblings working longer hours for much less money at one or more McJobs.

All of this detracts from the baseline level of adult involvement every child requires, regardless of ethnicity or age. Systemically shunned young Canadians do not exhibit the visible icons, cultural acuity and involvement, and behavioural habits of mainstream civil society. They are further marginalized by the system because of this in a self-reinforcing cycle. It manifests first in the creation of alter-egos and later in socially aberrant behaviours like crime, as evidenced by the prisoner population.

The system initially rejects and negates the natural personality. Existence precedes essence and necessitates the search for functionality in a synthesized identity. It is not the criminalized who chooses the name to operate under, but the name itself that empowers the individual who later increasingly operates outside of societal norms because no other viable options seem to exist. The adoption of street names is merely an effect, a symptom, of this impasse, the root causes of criminality, rather than of criminality in and of itself.

In place of the balanced and well adjusted square-citizen-taxpayer persona that most of us expect our children to develop, identities of selfmade success and excess are adopted by these kids who get left behind. This is in part purveyed by corporate "Hip Hop" culture and this statement is valid across ethnic groups. Music videos, magazines and role models merchandise and wear their wealth and patronize high-end designers. When did rap turn into a Gucci commercial? How much of Nike's revenue 
goes to marketing and making cool the "J's" that cost just a few dollars to manufacture? The kids take this to heart, while those in the top tiers of society benefit as the marketers intend them to.

What is the true cost of this subtle economic disenfranchisement, then? Growing up in survival mode in poor neighbourhoods or in the various component sub-groups of the future-incarcerated one must cast away or hide the part of our humanity that is vulnerable, empathic, and capable of forming authentic human connections. In its place an iron dome of machismo, an invincible fortress of solitude, is constructed along with a contextually appropriate façade of fearlessness, willingness to use violence, and cold impersonality. When you feel that the whole world is against you and unwilling to accept you for who you are, the advantages of a distancing mechanism that simultaneously protects your true, rejected self and recreates at will what you outwardly present are obvious.

I have encountered many characters in prison, and at times to the true person beneath: Tre (for the three in .38 caliber), Knuckles, Tattoo, Windy, many derivations of Tony (after Tony Montana), Mighty, Evil, Wags, Johnny Rotten, Rumble, Dog, Ghost, Squibbs, Gunner, Danger, Rider, Dragon, Smoke, Demon, Nasty, Mauler, Hollywood, Yankee, Midnight, Chinger, Tank, Ballah, Gypsy, Sprayz (think machine gun), NightCrawlah, Assassin, Sarge, Pike, One-Two, Shine, Cookie, Freakz, Q, Wolf, Wikkid, Never, Pumpah (like shotguns), The Tooth, Taliban, Ruckus, Rocks, Havoc, Bigz, Whitey, Shakey, Bless, Numbers, Rico, BadMash, and Chin. Each name immediately creates both overt and subtle cultural and psychological references - a persona ready-made.

Now that we are freed from the depersonalizing orange cover-alls of the provincial remand system we are able to wear our own clothes during nonwork hours in a federal prison. My peers here wear baggy, expensive track suits and sneakers that cost more than my Turkish three-button summer suit (it is very Connery Bond, quite intentionally). Many have tattoos on necks or on their hands, which are impossible to hide. The ubiquitous haircut here is the "Number One Bald Fade", worn by prisoners, soldiers and impoverished people everywhere. They certainly do not project the traditional and expected images of productive and well-behaved members of civil society.

There is almost a worship of criminality among some of my peers here at Collins Bay. It is a tribal loyalty at work. What is spoken of as the "Criminal Fraternity" is a fabricated familial relation. It makes up for absentee fathers, 
over-worked mothers, or siblings who went to jail or got pregnant in their teens and had to grow up too quickly. It is a world with well-defined rules and codes to follow, as well as predictable outcomes, as opposed to the unknowns inherent in participating in an economic system that is both foreign and unobtainable. It is easier than the overwhelming responsibility of early fatherhood without a requisite example.

I have seen many in prison who endure crippling addictions atop cultural and societal obstructions. I have read that a staggering number of prisoners were victims of sexual abuse early in their lives. These problems are often inter-generational, additive and self-reinforcing, as we are beginning to see in our Aboriginal population. Attention Deficit Disorders are endemic in modern society, not only among the disadvantaged and disenfranchised, and seem to affect everyone here at times. Since they were children, the future-incarcerate have been scrutinized and given negative attention by the authorities, much more than the "average Canadian" might be. Perhaps this is in part because of the outward identities they have chosen to display in their neighbourhoods rife with crime: targeted and haunted by police in untold numbers. On the other hand, I propose that it is the system itself that sets them apart and the manufactured identities are the result. The cycle has no discernible starting point but inevitably feeds off of itself, growing over time as the people mature.

Even I got a nickname after a difficult first year at the Don Gaol. I spent that year working out and eating properly, as well as getting banged out (hit hard in the face at least once) and punked off (denied something due to me like dessert, peanut butter, or a banana) regularly. My 160 pound deskjockey frame blossomed to 205 pounds of "don't fuck with me". Because of my many hours working out at the back of the range with my oversized orange cover-alls cinched around my waist using a belt woven from strips of bed sheet, shirtless and increasingly broad-chested, with my long hair tied atop my head in a top-knot, I became known as "Samurai". The name fit me well and I made no objections, and a friend of mine even wrote to me about the seven aspects of Bushido, the way of the warrior.

To me the identity was instructive and useful, as well as a good metaphor for who I have become. The normal and healthy outward projection of being is replaced with an often template-based proxy to deal with the world. Instead of the Square John I arrived as, I was the warrior: strong, trained and able to defend himself. I had seen battle and survived the war (thus far). Besides, 
who would you most fear and leave alone, Chester or Samurai? This brings about a new problem, though. It is easy inwardly to start mistaking the identity for the person, and basing responses on the formula rather than the underlying personality. If you wake up each day and don a sword it becomes more and more likely that you will enter into mortal combat.

The new identity also serves to distance people from each other as a protective mechanism - an extremely useful tactic in jail or prison or even on the dangerous streets. I think that soldiers use it, too. Nobody really wants to think of themselves as a thief, bully or killer. A part of us inevitably insists on looking at our actions through our mother's eyes. However, with no valid relationships to mourn the loss of or hold oneself accountable, the street avatar is free to move on into new and further tenuous circumstances and situations whenever convenient or necessary. It becomes a form of traveling light, this carrying of a persona or two to wear along our travels, and it gives one a means of distancing its true self from its actions and the consequences of them. Our reputations, thus, literally precede us in the layered modes of being.

The sad thing is that the person inside that fortress starves for direct human contact. The inner being, the true self, is kept from developing normally in a social context. It is a frightening reality that many of the men I am incarcerated with show a decided lack of maturity. They are emotionally and behaviourally caught in their teens. At first I thought this was environmental and a result of jocular, summer-camp-for-boys atmosphere of the prison system. I have come to realize that it is more indicative of deep wounds and deficits inflicted by years on the streets wearing masks and fronts.

It is strange how different an approach one must take when using a proxy name. When I needed to have a true heart-to-heart with someone in jail I insisted on using their first, given name, just like their parents or siblings would. It felt as though I could circumvent the edifice of an artificial front to speak to the real person by doing so. Imagine the difference between sitting across a table from someone versus addressing them on a television screen (as happens in many trials and hearings).

Most of the prisoners who have not adopted a nom de guerre go instead by their last names, but not necessarily by choice. Internally, there is a onestep-removed distancing by the choosing of a street name undertaken by the prisoner. Then the prisoner is invariably referred to by authorities by either last name or serial numbers assigned shortly after the time of their first arrest by the State. In a provincial remand centre where the accused are 
being warehoused without access to programming or support services, staff members distance themselves from their wards for the emotional protection of both sides of the equation.

I recall precisely the moment, after 19 months of incarceration and three months after my transfer to the Central North Correctional Centre in Penetanguishine, when a guard addressed me by my first name. While I insisted on my peers using my given name and my "Samurai" nickname being used with "new fish", the organs of the system itself invariably referred to me by a combination of my last name and my OTIS (Offender Tracking Information System) number. Hearing a female voice utter my first name gave me a strange, deeply emotional catharsis. It literally stopped me in my tracks as I sorted out the meal trays. It brought me nearly to tears then, as it does now in recalling it. Such moments are few and far between in the remand system, though.

A prisoner would not want to look upon an institutional Social Worker as a mother figure, nor would it be productive to fall in love with a guard. Conversely, staff members, guards included, realize that relationships created with people incarcerated within the criminal justice system by definition will come to abrupt and inevitable ends. There just is no point in making the effort to foster real human connections in such a system, for to do so invariably would result in some degree of emotional loss. This resultant depersonalization can last for spans of two or more years as prisoners like me facing more serious charges await trial and it has serious effects on psyches already at risk in a violent world within a monolithic court system that is, for the most part, beyond the individual's control.

After a few months of life in the Don I realized that I was investing myself emotionally to a far greater degree with my fellow prisoners than was necessary, wise or healthy. Instead of introducing myself and shaking hands with every man who "touched range", as we say, I began simply to grunt "Samurai" as a form of introduction. I gave up on shaking hands or even trying to memorize names. If the person was honest and real enough for me to have an actual conversation with, I would then make the effort if they remained long enough. It was just too exhausting to get to know every person, to try and sooth every needy and broken human I encountered. It hurt, that distancing of myself. It symbolized my "settling in for the long haul" in a transitory system. I embodied the Samurai's stoicism.

Even though one is never truly alone in jail, it is quite possibly the loneliest place on earth. So much anger. Street names. Faces on a TV screen. 
Prison numbers. An endless parade of weirdos, freaks, underachievers, misfits and outcasts. Orange jumpers. Prison Blues. "Inmate Abbotsbury". So much about this system, about the mechanisms that feed it, must change in order to preserve the humanity of the people who daily and by the thousands endure personal journeys through it. Systematic removal of the vehicles of honesty, truth, acceptance and identity, which are then replaced by walls, barriers, facades, masks and proxies, only serve to perpetuate and amplify marginalization and the existence of the system itself which feeds on its own product.

Oh, and by the way, Chester is not my real name.

\section{ENDNOTE}

* Editors' note: The term 'argot' refers to a collection of jargon or slang employed by a particular group to represent a range of social roles and experiences common to group members. These shorthand labels are imbued with meaning, stemming from the evaluation and interpretation of a particular experience, and constitute a shared belief and thus a specific set of behaviours or reactions in relation to a given experience (Sykes, 1958). Argot may consist of new words or existing words that have been assigned a new or alternate meaning. Within carceral institutions, this language reflects the personality of the individual who employs it, as well as the conflicts and tensions inherent in the institutional setting (ibid). Prison argot is used to establish a social hierarchy within and/or between particular groups of prisoners, as well as between prisoners and staff, creating distinct factions to distinguish between those who deserve respect and those who do not (Huckelbury, 2009). The prison environment pressures newcomers, including prisoners and staff, to conform to a pre-existing social hierarchy and surrender to a broader group ethos, which demonstrates shared experience and results in peer acceptance (ibid). This article highlights these themes related to the role of language in carceral settings.

\section{REFERENCES}

Huckelbury, Charles (2009) "Talking Points: How Language Functions as a Status Determinant in Prison", Journal of Prisoners on Prisons, 18(1\&2): 22-28.

Sykes, Gresham M. (1958) The Society of Captives: A Study of Maximum Security Prison, Princeton, New Jersey: Princeton University Press. 


\section{ABOUT THE AUTHOR}

Chester Abbotsbury is the pseudonym of a man currently incarcerated within a CSC penitentiary. Jailed for nearly two years at the provincial-level awaiting trial, he pleaded to " 10 more years" within the federal system. His Gonzo New Journalism has appeared in print in Canada, Germany, Japan, Great Britain and the United States prior to his arrest. He has published while incarcerated and is working on a series of essays, of which "What's in a Name?" is one, entitled Pen 101. He also writes speculative fiction and voluminous correspondence. 